\title{
Giovanni Dotoli, Montaigne et les libertins
}

\section{Dario Cecchetti}

\section{OpenEdition}

\section{Journals}

\section{Edizione digitale}

URL: http://journals.openedition.org/studifrancesi/9846

DOI: $10.4000 /$ studifrancesi.9846

ISSN: 2421-5856

\section{Editore}

Rosenberg \& Sellier

\section{Edizione cartacea}

Data di pubblicazione: 1 octobre 2007

Paginazione: 430-431

ISSN: 0039-2944

\section{Notizia bibliografica digitale}

Dario Cecchetti, «Giovanni Dotoli, Montaigne et les libertins», Studi Francesi [Online], 152 (LI | II) | 2007, online dal 30 novembre 2015, consultato il 09 janvier 2021. URL: http://journals.openedition.org/ studifrancesi/9846 ; DOI: https://doi.org/10.4000/studifrancesi.9846

\section{Questo documento è stato generato automaticamente il 9 janvier 2021.}

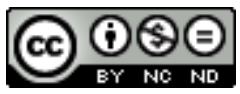

Studi Francesi è distribuita con Licenza Creative Commons Attribuzione - Non commerciale - Non opere derivate 4.0 Internazionale. 


\title{
Giovanni Dotoli, Montaigne et les libertins
}

\author{
Dario Cecchetti
}

\section{NOTIZIA}

GIOVANNI DOTOLI, Montaigne et les libertins, Paris, Champion («Études montaignistes», 49), 2006, pp. 177.

1 Da alcuni anni Giovanni Dotoli ha saputo animare una scuola di giovani montaignisti (Cavallini, De Vincenzo, Leopizzi) che ha arricchito di ricerche puntuali e documentarie il campo degli studi sul grande moralista, ha organizzato convegni e lavori collettivi, si è fatto promotore di un'impresa utilissima agli studiosi, quale la stampa anastatica dell'edizione bordelese del 1588, con le annotazioni autografe di Montaigne, per i tipi di Schena. Ritorna ora su di un argomento cui aveva già consacrato interventi, quello dei rapporti fra il libertinage e Montaigne, offrendoci un volume che fa il punto di decennali ricerche, seguendo uno schema tematico che concentra il discorso sui seguenti problemi: la figura del saggio, verità e ragione, natura ed espe-rienza, la nozione di 'uomo', religione e destino, Storia-Universo-Stato, la nozione di virtù. Come Montaigne stesso ricorda, negli Essais «toutes les contrariétés s'y trouvent selon quelque tour et en quelque façon»: per questo l'A. può dire che nel Grand Siècle Montaigne appartiene a tutti, ammiratori e avversari, e che «libertini e nemici dei libertini lo scelgono come punto di riferimento, per presentarlo come capofila o per attaccarlo», al punto che possiamo a buon titolo considerarlo (è l'assunto del capitolo d'apertura) écrivain du XVII siècle. Malgrado il moltiplicarsi delle edizioni (35 in Francia, tra il 1580 e il 1669), taluni critici come Maturin Dréano (La religion de Montaigne, Paris, Nizet, 1969) hanno creduto di potere affermare che «le livre de Montaigne est moins lu que ne le feraient croire ses nombreuses éditions», e questo a causa delle citazioni, digressioni, bruschezze di tono, arcaismi, a causa insomma di non avere una struttura 'classica'. È contro questo assunto, in primo luogo, che muove il libro di G. Dotoli, convinto di quanto già PierreDaniel Huet, all'inizio del Settecento, affermava circa la grande voga di Montaigne 
durata tutto il Seicento. D'altronde Dotoli ci ricorda che, nonostante le lodi e l'apprezzamento di alcuni cattolici, già nel Grand Siècle gli Essais sono giudicati un libro pericoloso, legato alla storia del libertinismo e che «l'evoluzione dei libertini è parallela a quella della fortuna degli Essais». Se gli Essais sono un libro, per dirla con Tzvetan Todorov, in cui ciascuno "peut choisir son propre parcours», i libertini per certo hanno saputo scegliervi il loro. Il presente volume indica tutta una serie di valutazioni di autori secenteschi, appartenenti in gran parte, ma non tutti, all'area del libertinismo, che danno degli Essais una lettura 'libertina'. A partire da Antoine de Laval (1605) fino alla messa all'Indice (1676), si moltiplicano i giudizi in questa prospettiva: elogiativi da parte dei libertins (per Gabriel Naudé Montaigne ha qualcosa di divino, è la «sagesse même»), di condanna da parte dei pensatori e teologi ortodossi (Bossuet parla di Montaigne «come se fosse un libertino di cuore e pensiero, e non soltanto il capofila accaparrato suo malgrado dai libertini»). Numerose sono le opere di libertini che utilizzano Montaigne: Gassendi, Cyrano de Bergerac, La Mothe Le Vayer, SaintÉvremond, Bayle, Fontenelle; ed è in queste opere che Dotoli ritrova le piste da seguire. Sono questi, in parte almeno, gli autori in cui rintraccia affinità, dipendenze e sviluppi, per quello che concerne le tematiche di cui si è detto e che scandiscono i vari capitoli del libro. Per quanto riguarda, pertanto, il dibattuto problema del rapporto del libertinismo secentesco con Montaigne non si può non concludere con l'A.: «La verité est dans l'intertestualité». Intertestualità che G. Dotoli indaga con finezza e acume lungo tutto il suo saggio, illuminante e di piacevole lettura. 